\title{
BMJ
}

\section{Association between mid-life marital status and cognitive function in later life: population based cohort study}

\author{
Krister Håkansson, research fellow, ${ }^{1,2}$ Suvi Rovio, research fellow, ${ }^{2}$ Eeva-Liisa Helkala, neuropsychologist, ${ }^{3}$ \\ Anna-Riitta Vilska, lecturer, ${ }^{4}$ Bengt Winblad, professor, ${ }^{2}$ Hilkka Soininen, professor ${ }^{5,6}$ Aulikki Nissinen, \\ professor, ${ }^{7}$ Abdul H Mohammed, professor, ${ }^{1,2}$ Miia Kivipelto, associate professor ${ }^{2,5}$
}

${ }^{1}$ School of Social Sciences, Department of Psychology, Växjö University, Sweden

${ }^{2}$ Aging Research Centre,

Department of Neurobiology,

Caring Sciences and Society,

Karolinska Institute, Stockholm,

Sweden

${ }^{3}$ Department of Public Health and General Practice, University of Kuopio, Kuopio, Finland

${ }^{4}$ Savonia University of Applied Sciences, Kuopio, Finland

${ }^{5}$ Department of Neuroscience and Neurology, University of Kuopio, Kuopio, Finland

${ }^{6}$ Department of Neurology, Kuopio University Hospital,

Kuopio, Finland

${ }^{7}$ Department of Health Promotion and Chronic Disease Prevention, National Institute for Health and Welfare, Helsinki, Finland

Correspondence to: M Kivipelto, Department of NVS, KI-Alzheimer's Disease Research Centre, Karolinska Institute, S-141 86

Stockholm, Sweden

Miia.Kivipelto@ki.se

Cite this as: $B M J$ 2009;339:b2462 doi:10.1136/bmj.b2462

\section{ABSTRACT}

Objectives To evaluate whether mid-life marital status is related to cognitive function in later life.

Design Prospective population based study with an average follow-up of 21 years.

Setting Kuopio and Joensuu regions in eastern Finland. Participants Participants were derived from random, population based samples previously investigated in $1972,1977,1982$, or $1987 ; 1449$ individuals (73\%), aged 65-79, underwent re-examination in 1998.

Main outcome measures Alzheimer's disease and mild cognitive impairment.

Results People cohabiting with a partner in mid-life (mean age 50.4) were less likely than all other categories (single, separated, or widowed) to show cognitive impairment later in life at ages 65-79. Those widowed or divorced in mid-life and still so at follow-up had three times the risk compared with married or cohabiting people. Those widowed both at mid-life and later life had an odds ratio of 7.67 (1.6 to 40.0) for Alzheimer's disease compared with married or cohabiting people. The highest increased risk for Alzheimer's disease was in carriers of the apolipoprotein E e4 allele who lost their partner before mid-life and were still widowed or divorced at follow-up. The progressive entering of several adjustment variables from mid-life did not alter these associations.

Conclusions Living in a relationship with a partner might imply cognitive and social challenges that have a protective effect against cognitive impairment later in life, consistent with the brain reserve hypothesis. The specific increased risk for widowed and divorced people compared with single people indicates that other factors are needed to explain parts of the results. A sociogenetic disease model might explain the dramatic increase in risk of Alzheimer's disease for widowed apolipoprotein E e4 carriers.

\section{INTRODUCTION}

As life expectancy is increasing in various regions of the world, dementia is becoming a growing public health concern. In 2005 an estimated 25 million people had dementia, and the number is expected to double every 20 years in the future, reaching 81.1 million in $2040 .{ }^{1}$ In the Western world the prevalence has been estimated as around 15\% among 80 year olds and 25\% for those over $85,{ }^{12}$ with Alzheimer's disease being the most common diagnosis. ${ }^{2}$ Besides the consequences for the patients and their families, patients might require intensive care, especially in the more advanced stages of the disease. The healthcare costs for people with cognitive impairments in the United Kingdom are estimated to rise from $£ 5.4 \mathrm{bn}$ in 2002 to $£ 16.7 \mathrm{bn}$ in 2031. ${ }^{3}$ There is no known cure, although knowledge about biological mechanisms and behavioural risk factors is steadily accumulating.

Several studies have suggested an association between lifestyle and cognitive decline. Education, ${ }^{4-8}$ physical activity, ${ }^{9-12}$ mentally demanding work, ${ }^{4}$ higher managerial positions, ${ }^{4}$ and various leisure and intellectual activities ${ }^{491213}$ have all been reported to predict a more favourable cognitive status later in life. A rich social network has also been linked to a lower risk of cognitive impairment and dementia. ${ }^{12-17}$ Followup times in these studies ranged from three to five years, with only one exception, ${ }^{16}$ meaning that people were typically already in their later years $(>65)$ at baseline measurements. The possibility of "reverse causation" is illustrated by the findings of the only study on social factors with a longer (27.5 years) follow-up. ${ }^{16}$ That study found an association between social engagement and dementia in later life, whereas no such association was found for mid-life data. The possibility of subclinical dementia behind any association established through studies with short follow-up is further strengthened by findings of abnormal cognitive function five ${ }^{18}$ to eight ${ }^{19}$ years before a diagnosis of dementia. One study reported subclinical decline up to nine years before a diagnosis, with an acceleration three years before ${ }^{20}$ - that is, all within typical followup times of previous prospective studies on social factors and cognitive decline.

Many studies have reported that living as a couple and the quality of the relationship are both positively correlated with health and longevity. ${ }^{21} 22$ Few prospective studies, however, have specifically examined the association between marital status and the risk of dementia. ${ }^{23-27}$ The categorisation of marital status differed somewhat between these studies, but all but one ${ }^{27}$ 


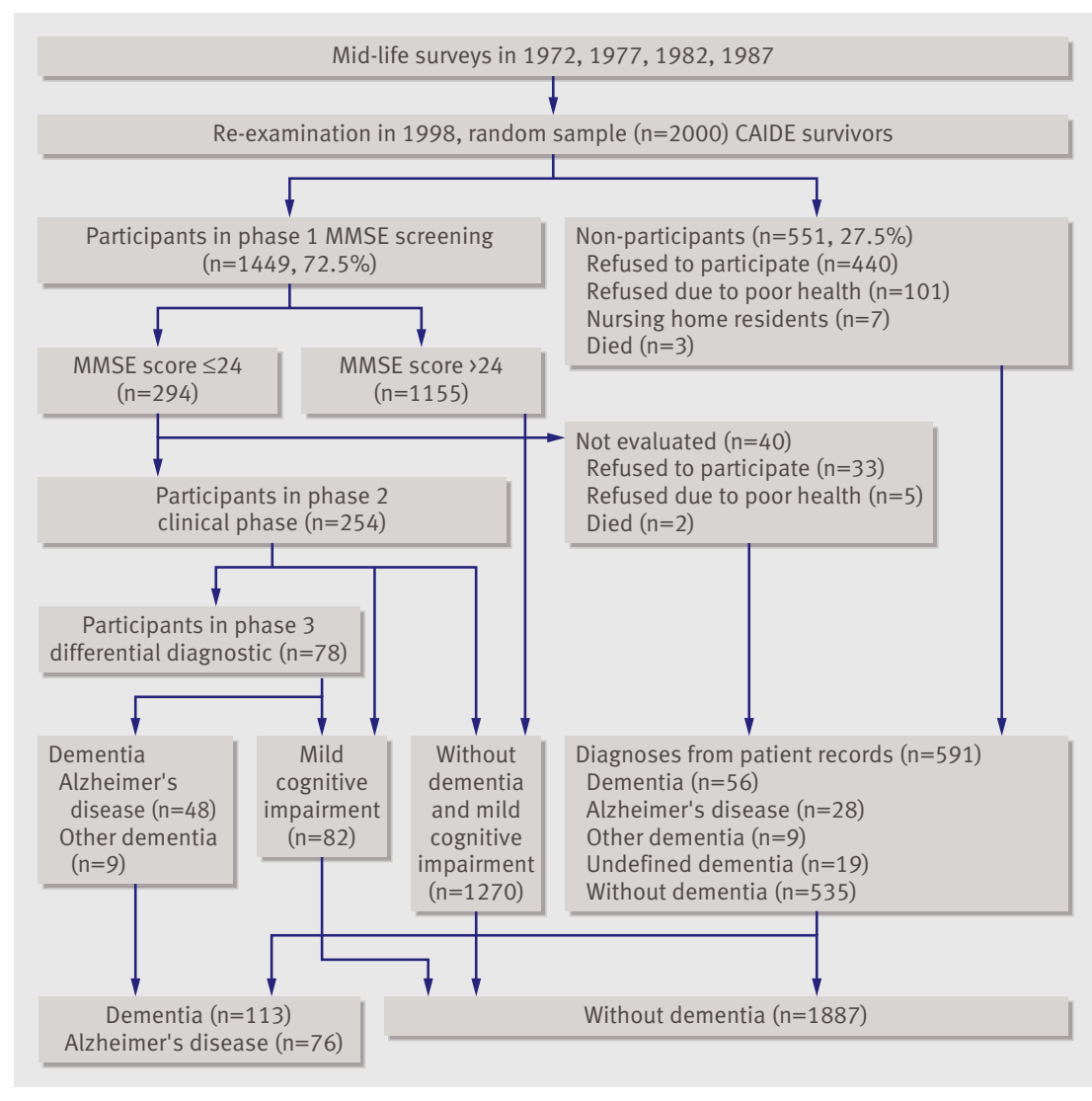

Fig 1 Flow of participants (MMSE=mini-mental state examination)

found an increased risk of dementia from living without a partner, either as single ${ }^{2325}$ single or divorced, ${ }^{26}$ or unmarried..$^{24}$ Follow-up times in these studies range from three years ${ }^{25}$ to 10 at the most. ${ }^{24}$

We specifically evaluated the relevance of marital status in mid-life, with adjustments for various other variables that were also measured at baseline, for $\operatorname{cog}$ nitive status later in life.

\section{METHODS}

\section{Study design}

We used a population based design with participants from two regions in eastern Finland. Participants were examined in mid-life (mean (SD) age 50.4 (6.0) years) and then again around 21 years later. The main variables were marital status (married/cohabiting, single, divorced, or widowed) measured at mid-life and follow-up and additional diagnostic measures of cognitive impairment (mild cognitive impairment, Alzheimer's disease, and other forms of dementia) at follow-up. By combining marital status at both times, we created several categories of marital transition (such as married at both times, married in mid-life and widowed later in life, etc). We then related mid-life marital status and transitions in marital status from mid-life to later life to cognitive status later in life. We adjusted the estimations of these associations for several other variables from the mid-life measurements. Finally, we investigated if carriers of the apolipoprotein E e4 allele, the most important currently known genetic risk factor for Alzheimer's disease, were especially at risk for cognitive impairment later in life if they also lived alone after losing their partner.

\section{Participants}

This research was part of the cardiovascular risk factors, aging and dementia (CAIDE) study. The participants of the CAIDE study comprised a random sample of 2000 survivors from four separate population samples, originally investigated in 1972, 1977, 1982, or 1987. These investigations assessed cardiovascular risk factors within the North Karelia Project and the FINMONICA study. The four original samples were randomly drawn from the population register of two regions in eastern Finland and comprised 30078 participants aged 3059. Each original sample was stratified so that there were at least 250 participants from each sex and from each of the three 10 year age intervals. The participation rate in the baseline investigations was $82-90 \%$.

By the end of 1997, 2000 randomly selected survivors, all from or nearby the cities of Kuopio and Joensuu and aged 65-79, were invited for re-examination during the following year. The mean follow-up time was 20.9 years (SD 4.9). Altogether 1449 (73\%), then aged $65-80$ (mean age 71.3 , SD 4.9), were able to or agreed to participate. This sample constitutes the database for the present study, together with the data from the baseline measurements and register linked data from later in life for the 551 non-participants. Figure 1 shows details of the flow of participants.

There were few differences between participants and non-participants at mid-life. ${ }^{28}$ Non-participants were somewhat older and less educated, had higher cholesterol concentration, blood pressure, and body mass index, and fewer of them did office or service work. Fewer were married or cohabiting $(73.5 \%$ v 79.9\% for participants).

\section{Mid-life measurements}

The survey methods used during baseline (mid-life) examinations complied with the WHO MONICA protocol, described in more detail elsewhere. ${ }^{29}$ In brief, the baseline survey included a self administered questionnaire on health behaviour, health status, signs of depression, and medical history. Trained nurses checked the questionnaires to ensure that they were fully completed and understood. Participants' blood pressure, height, and weight were measured, and body mass index calculated. A venous blood specimen was taken to determine serum cholesterol concentration. A questionnaire classified marital status into four categories: married/cohabiting, separated/divorced, single, or widowed.

\section{Later life measurements}

During the re-examination in 1998, the survey methods followed those applied in the previous surveys in all aspects. In addition, we identified participants' apolipoprotein genotype by using polymerase chain reaction and Hhal digestion, as described by Tsukamoto 
et al. ${ }^{30}$ Cognitive status was assessed with a three step protocol for the diagnosis of dementia: a screening phase, a clinical phase, and a differential diagnostic phase. The 294 participants who scored 24 or less on the mini-mental state examination $(\mathrm{MMSE})^{31}$ were referred for further examinations, including thorough neurological, cardiovascular, and neuropsychological assessments. Those with possible dementia, based on these assessments and as judged by an expert board, were referred to the differential diagnostic phase, including magnetic resonance imaging of the brain. In the final step, the review board re-analysed all data from the three phases before establishing the final diagnosis. Dementia was diagnosed according to the Diagnostic and Statistical Manual of Mental Disorders, 4th edition (DSM-IV), criteria in 57 participants. The diagnostic criteria for Alzheimer's disease was fulfilled in 48 of these according to criteria from the National Institute of Neurological and Communicative Disorders and Stroke-Alzheimer's Disease and Related Disorders Association. ${ }^{32}$ All patients with a diagnosis of Alzheimer's disease showed generalised or medial temporal lobe atrophy, or both, without relevant vascular pathology, as revealed by magnetic resonance imaging. Mild cognitive impairment was diagnosed in 82 , according to a procedure previously described, ${ }^{29}$ derived from the criteria advised by the Mayo Clinic Alzheimer's disease research centre. ${ }^{33}$ The main criteria were objective impairment below $1.5 \mathrm{SD}$ of the age appropriate mean in either memory or one other area of cognitive functioning, along with memory complaints. Marital status was determined by the same procedure as in mid-life.

We collected data on diagnoses of dementia in the 551 non-participants from local hospitals and healthcare centres. The total number of cases increased to $113(5.9 \%$ of the population) when we took these diagnoses into account. As we lacked information on diagnosis procedures, apolipoprotein, and late marital status, we used this group only for reference to cross validate main results.

\section{Statistical analysis}

Directly relating the four categories of marital status in mid-life to all categories of cognitive impairment resulted in unacceptably low numbers of participants

Table 1 | Marital status transitions* between mid-life and follow-up

\begin{tabular}{lccccc} 
& \multicolumn{4}{c}{ Later life marital status } & \\
\cline { 2 - 5 } Mid-life marital status & $\begin{array}{c}\text { Married/ } \\
\text { cohabiting }\end{array}$ & Single & $\begin{array}{c}\text { Separated/ } \\
\text { divorced }\end{array}$ & Widowed & Total \\
Married/cohabitant & 809 & 0 & 59 & 279 & 1147 \\
\hline Single & 9 & 100 & 1 & 1 & 111 \\
\hline Separated/divorced & 9 & 0 & 50 & 4 & 63 \\
\hline Widowed & 5 & 0 & 1 & 105 & 111 \\
\hline Total & 832 & 100 & 111 & 389 & 1432
\end{tabular}

*Four main transition categories: cohabiting with partner on both occasions $(n=809)$, cohabiting with partner in mid-life but not in later life ( $n=338$ ), living without partner on both occasions $(n=262)$, and living without partner in mid-life but cohabiting in later life ( $n=23$; omitted in calculations because of too few participants to combine with dementia categories separately and inadequacy of combining it with any other category). Data on both mid-life and late marital status were missing for 17 . in some of the cells. Because we were interested in whether the reason for living without a partner would make any difference, in addition to collapsing the three non-cohabiting categories into one-that is, comparing cohabitants with non-cohabitants in mid-life-we used three categories: living with a partner, single/ divorced, or widowed. This choice was based on theoretical and statistical considerations. Being widowed is the result of a traumatic, imposed, and involuntary marital transition that distinguishes it from the other two non-cohabitating categories (single and divorced). This assumption was reinforced by preliminary analyses that revealed a linear relation with the risk of cognitive impairment (measured by $\chi^{2}$ and logistic regressions) so that widowed people had the highest risk, single and separated or divorced people emerged as a middle category, and married people had the lowest risk (see table 2).

By combining marital status in mid-life and later life, 13 theoretically possible categories of marital transition emerged (table 1). Based on these, we classified marital transition as cohabiting with a partner on both occasions, cohabiting with a partner in mid-life but not in later life, and living without a partner on both occasions. (The fourth category, living without a partner in mid-life but cohabiting in later life contained too few people to be used in calculations and it was not possible to combine it with any other category.) We performed separate calculations with this variable treated either as nominal or ordinal. The ordinal assumption was that each of the three categories should be associated with different amounts of time spent in a cohabiting partner relation from mid-life onwards.

Cognitive impairment was first treated as an "all inclusive" variable, comprising the 139 participants with a diagnosis of mild cognitive impairment or any kind of dementia. For more detailed analysis, we analysed mild cognitive impairment and Alzheimer's disease separately. In each of the three analyses, the 1270 participants without any signs of cognitive impairment served as reference. In alternative calculations we entered cognitive function as ordinal, assuming that mild cognitive impairment represents a milder form of impairment than Alzheimer's disease.

We used logistic regression to analyse the association between marital status and cognitive status later in life. Apart from adjustment for variables of most obvious relevance to predict dementia, such as age, apolipoprotein E e4 status, and education, we decided to adjust only for those variables for which we had data for all, or almost all, of the 1449 participants who were screened for dementia. Among these, we identified several variables related to marital status (table 2). Two further variables were selected for their contribution to the regression model after adjustmentsnamely, blood pressure and residence area. In the case of multicollinearity, we chose the variable that contributed most in the regression model. Because of this criterion, we chose age at follow-up instead of follow-up time and systolic blood pressure rather than diastolic blood pressure. 
Table 2 | Differences between marital status groups at mid-life in participants from Kuopio or Joensuu, Finland. Figures are means (SD) unless stated otherwise

\begin{tabular}{|c|c|c|c|c|c|c|}
\hline & $\begin{array}{l}\text { Married } \\
(n=1270)\end{array}$ & $\begin{array}{c}\text { Single } \\
(n=166)\end{array}$ & $\begin{array}{c}\text { Separated/ } \\
\text { divorced }(n=97)\end{array}$ & $\begin{array}{l}\text { Widowed } \\
(n=174)\end{array}$ & Total & P value* \\
\hline \multicolumn{7}{|l|}{ Variables: } \\
\hline No (\%) who participated in follow-up & $1157(74.1)$ & $112(67.5)$ & $63(64.9)$ & $116(66.7)$ & 1999 & 0.021 \\
\hline No (\%) with cognitive impairment at follow-up & $98(8.6)$ & $12(11.1)$ & $7(11.7)$ & $22(20,4)$ & 1409 & 0.001 \\
\hline No (\%) of ApoE e4 carriers (one or two alleles) & $413(36.6)$ & $34(31.2)$ & $20(32.3)$ & $32(29.4)$ & 1407 & 0.31 \\
\hline Age at follow-up (years) & $71.2(4.0)$ & $71.2(4.0)$ & $70.4(4.1)$ & $72.9(4.1)$ & 1447 & $<0.001$ \\
\hline Follow-up time (years) & $21.2(4.8)$ & $20.7(4.7)$ & $19.9(4.8)$ & $18.6(5.1)$ & 1447 & $<0.001$ \\
\hline No (\%) of women & $652(56.4)$ & $91(81.3)$ & $46(73.0)$ & $111(95.7)$ & 1448 & $<0.001$ \\
\hline \multicolumn{7}{|l|}{ Mid-life variables: } \\
\hline Education (years) & $8.6(3.47)$ & $9.1(3.42)$ & $8.2(2.87)$ & $7.5(3.31)$ & 1427 & 0.003 \\
\hline Age (years) & $50.0(5.9)$ & $50.5(5.9)$ & $50.5(5.8)$ & $54.3(5.2)$ & 1447 & $<0.001$ \\
\hline Total cholesterol (mmol/l) & $6.7(1.18)$ & $6.9(1.28)$ & $6.5(1.36)$ & $7.0(1.27)$ & 1448 & 0.03 \\
\hline Systolic blood pressure (mm/Hg) & $145(19.5)$ & $145(23.0)$ & $141(20.4)$ & $145(22.8)$ & 1448 & 0.50 \\
\hline Diastolic blood pressure $(\mathrm{mm} / \mathrm{Hg})$ & $90(10.8)$ & $89(11.5)$ & $87(13.3)$ & $88(11.2)$ & 1448 & 0.27 \\
\hline BMI & $26.7(3.6)$ & $25.7(4.7)$ & $26.4(3.6)$ & $26.5(3.8)$ & 1448 & 0.06 \\
\hline Occupational physical activity & $1.96(0.91)$ & $1.81(0.90)$ & $2.02(0.91)$ & $1.76(0.84)$ & 1436 & 0.04 \\
\hline No (\%) of smokers & $530(45.8)$ & $35(31.3)$ & $25(39.7)$ & $31(26.7)$ & 1447 & $<0.001$ \\
\hline No (\%) of office workers & $515(44.5)$ & $64(57.1)$ & $28(44.4)$ & $45(38.8)$ & 1448 & 0.04 \\
\hline No (\%) from Kuopio & $560(48.4)$ & $60(53.6)$ & $32(50.8)$ & $55(47.4)$ & 1448 & 0.73 \\
\hline Signs of depression $\ddagger$ & $6.8(2.3)$ & $7.0(2.4)$ & $7.6(2.7)$ & $7.1(2.4)$ & 1403 & 0.07 \\
\hline
\end{tabular}

${ }^{*} X^{2}$, analysis of variance, or Kruskal-Wallis statistics as appropriate.

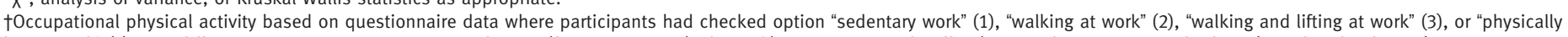
heavy work" (4). Five different occupation categories were farming/forestry, mining/industrial/construction work, office/service, housewives, and others (mixed and unknown).

fIndex created by combining responses to three statements regarding perception of hopeless future, having goals that are impossible to achieve, and being without friends.

All the analyses were adjusted for age (at re-examination), education, sex, and apolipoprotein E e4 status (e4 carriers $v$ non-carriers). In the next step we additionally adjusted for mid-life systolic blood pressure, cholesterol concentration, body mass index, smoking, occupation (farming/forestry as reference), region of residence, occupational physical activity, and signs of depression.

Each step of adjustment added significantly to explain the total variance in the regression model. Because progressive adjustments did not significantly change the association studied, we have presented only the final models, including all the adjustments.

\section{RESULTS}

Mid-life marital status: sociodemographic and clinical characteristics

Table 2 shows sociodemographic and clinical characteristics of the participants according to categories of

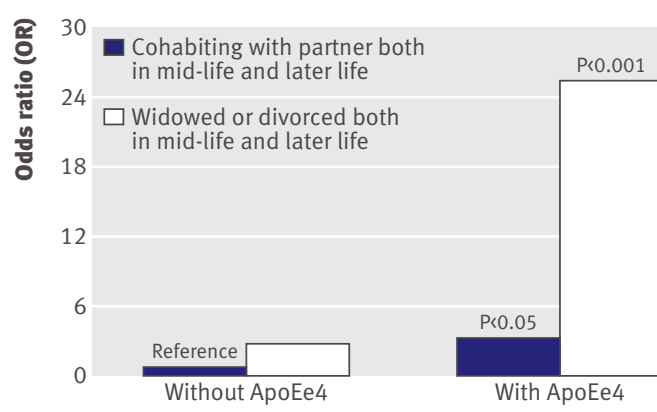

Fig 2 | Risk of Alzheimer's disease for apolipoprotein E e4 (ApoEe4) carriers $v$ non-carriers for people widowed or divorced in mid-life and later life mid-life marital status. Most widowed participants were women and somewhat older at follow-up; single people were somewhat more educated and more had office jobs; more married participants were smokers. We adjusted for all these variables. We found no differences in vascular risk factors in mid-life. Cognitive impairment later in life was more common among participants living without a partner in mid-life. The largest discrepancy was found for widowed people with more than twice as many cases as expected.

Mid-life marital status and cognitive impairment in later life People living without a partner at mid-life had around twice the risk of developing cognitive impairment in later life compared with people living with a partner, even after all adjustments (table 3). Independent calculations for mild cognitive impairment and Alzheimer's disease, with consequential loss of statistical power, showed similar odds ratios, significant for mild cognitive impairment and of borderline significance for $\mathrm{Alz}_{-}$ heimer's disease. When the model treated single or divorced and widowed people separately, and in addition independently relating them to mild cognitive impairment and Alzheimer's disease, significance was lost for the single or divorced category. The high odds ratios for those widowed in mid-life was $2.76(\mathrm{P}=0.002)$ for broad cognitive impairment and $3.30(\mathrm{P}=0.001)$ for mild cognitive impairment (table 3 ).

We cross checked the results for mid-life marital status and confirmed them with ordinal logistic regression (cognitive function as normal-mild cognitive impairment-Alzheimer's disease). When calculated this 
Table 3 Association between mid-life marital status and cognitive impairment later in life.* Figures are odds ratios ( $95 \%$ confidence intervals)*

\begin{tabular}{lccc} 
& $\begin{array}{c}\text { Cognitive impairment } \\
(\mathrm{n}=131 / 1303 \dagger)\end{array}$ & $\begin{array}{c}\text { Mild cognitive } \\
\text { impairment }(\mathrm{n}=78 /\end{array}$ & $\begin{array}{c}\text { Alzheimer's disease } \\
\text { ( } \mathrm{n}=44 / 1216 \dagger)\end{array}$ \\
Without partner & $2.09(1.3$ to 3.4$)$ & $2.14(1.2$ to 3.8$)$ & $2.06(0.9$ to 4.7$)$ \\
\hline Widowed & $2.76(1.5$ to 5.2$)$ & $3.30(1.6$ to 6.9$)$ & $2.52(0.8$ to 7.7$)$ \\
\hline Single/divorced & $1.56(0.9$ to 2.8$)$ & $1.50(0.7$ to 3.4$)$ & $1.78(0.7$ to 4.9$)$ \\
\hline
\end{tabular}

*Adjusted for age at follow-up, years of education, ApoE e4, sex, BMI, systolic blood pressure, cholesterol, occupation, physical activity at work, region of residence, smoking, and signs of depression at mid-life. Some participants without data on all adjustment variables were excluded from this analysis.

†Number with condition out of total analysed.

way, the results confirmed even more strongly the protective association of a cohabiting couple relationship in mid-life $(\mathrm{P}=0.002$ for cohabitants $v$ non-cohabitants $)$.

Transition of marital status and cognitive function in later life

The group who had lived without a partner both in mid-life and later life had about three times the risk (fully adjusted models) for general cognitive impairment (dementia plus mild cognitive impairment) and also specifically for mild cognitive impairment and Alzheimer's disease, compared with those who were cohabiting both in mid-life and later life. On the other hand, for those who divorced or were widowed after mid-life, after adjustment odds ratios reached only borderline significance (table 4).

We cross checked results with ordinal logistic regression, entering cognitive status as an ordinal outcome variable. The ordinal logistic analysis confirmed that living without a partner from mid-life onwards was predictive of cognitive impairment $(\mathrm{P}<0.001$ in all comparisons).

\section{Sex differences}

The uneven distribution between men and women in this age group and in the different non-cohabitant categories (see table 2) allowed for sex comparisons only for the broadest categories of non-cohabitants in relation to general cognitive impairment. Compared with cohabitants, the odds ratio for mid-life non-cohabitants was 1.87 (1.1 to 3.3) for women and 2.59 (1.0 to 6.7 ) for men (fully adjusted model). For those who were cohabiting in mid-life and not cohabiting in late-life, the

Table $4 \mid$ Association between marital transition and cognitive impairment later in life. Figures are odds ratios $(95 \%$ confidence intervals)*

\begin{tabular}{lccc} 
& $\begin{array}{c}\text { Cognitive } \\
\text { impairment } \\
(\mathrm{n}=129 / 1274)\end{array}$ & $\begin{array}{c}\text { Mild cognitive } \\
\text { impairment } \\
(\mathrm{n}=78 / 1223)\end{array}$ & $\begin{array}{c}\text { Alzheimer's disease } \\
\text { ( } \mathrm{n}=42 / 1187)\end{array}$ \\
\hline Partner in mid-life, but not at follow-up $\dagger$ & $1.60(1.0$ to 2.7$)$ & $1.75(0.9$ to 3.3) & $1.60(0.7$ to 3.8) \\
\hline Without partner in mid-life and follow-up $\dagger$ & $2.89(1.7$ to 5.0) & $3.17(1.7$ to 6.0) & $2.83(1.1$ to 7.4) \\
\hline Ordinal assumption $\ddagger$ & $1.70(1.3$ to 2.2$)$ & $1.78(1.3$ to 2.5$)$ & 1.67 (1.0 to 2.7) \\
\hline
\end{tabular}

*Adjusted for age at follow-up, years of education, ApoE e4, sex, BMI, systolic blood pressure, cholesterol, occupation, physical activity at work, region of residence, smoking, and signs of depression at mid-life. Some participants without data on all adjustment variables were excluded from this analysis.

†Marital status entered as dichotomous variable with cohabitants both in mid-life and later life as reference group.

łMarital transition entered as ordinal (partner on both occasions; partner in mid-life/without partner at followup; without partner on both occasions). Odds ratios thus indicate increase in risk for each level. odds ratio was 1.28 (0.7 to 2.5$)$ for women and 2.38 (1.0 to 5.7 ) for men. For non-cohabiting both in midlife and later life the odds ratio was 2.38 (1.2 to 4.7$)$ for women and 3.56 (1.3 to 9.5) for men.

\section{Differences within the non-cohabitant group}

To focus separately on those who were single both at mid-life and follow-up, we performed logistic regression with those living with a partner on both occasions as reference. After adjustment, the odds ratio for cognitive impairment (dementia plus mild cognitive impairment) was 1.94 (0.9 to 4.4) for being single on both occasions. An analogous separate logistic regression on people who were widowed or divorced on both occasions yielded odds ratios of 3.53 (1.7 to 7.4) and 2.74 (0.96 to 6.4$)$, respectively.

Widowed people had the highest odds ratios of the three groups who had lived without a partner from mid-life. The odds ratio for Alzheimer's disease was 7.67 (1.6 to $40.0, \mathrm{P}=0.01$ ) compared with those living with a partner on both occasions.

\section{Widowed status and apolipoprotein E e4}

To explore the mechanisms behind the high odds ratio for widowed people, specifically for Alzheimer's disease, we formed subgroups with reference to apolipoprotein E e4 status. With cohabiting apolipoprotein E e4 non-carriers as reference, the odds ratio for apolipoprotein E e4 carriers who had been widowed or divorced both in mid-life and later life was 25.55 (5.7 to $114.5, \mathrm{P}<0.001$ ) (fig 2).

Figure 3 shows that the corresponding odds ratio for apolipoprotein E e4 carriers who were widowed or divorced both at baseline and follow-up was considerably lower with mild cognitive impairment as outcome (4.68, 1.65 to 13.3$)$ than with Alzheimer's disease as outcome. In comparison with those widowed both at mid-life and later in life, odds ratios were generally lower for those who were only widowed or divorced after mid-life, both for mild cognitive impairment (2.66, 1.1 to 6.2) and for Alzheimer's disease (5.0, 1.4 to 17.5$)$. The large confidence intervals in these calculations indicate less reliable point estimates of odds ratios.

\section{Non-participants}

Odds ratios were similar for non-participants when we calculated them in the same way but without adjustment for apolipoprotein status. When we dichotomised participants into living with or without a partner in mid-life, the odds ratio for dementia was 1.85 ( 0.9 to 4.0$)$ for those who lived without a partner in mid-life. When we compared those either divorced or widowed with those who were still married in midlife, the corresponding odds ratio was 2.22 (0.9 to 5.4). The non-participant group, however, was rather small and adjustments reduced the sample size further from 551 to 488 . As apolipoprotein data, later life data, and specific diagnoses of Alzheimer's disease were all 


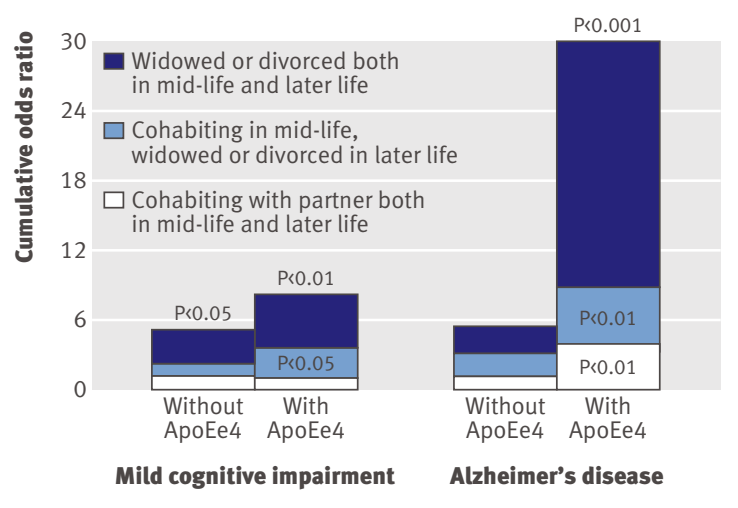

Fig 3 | Differences in risk of cognitive impairment for apolipoprotein E e4 (ApoE e4) carriers $v$ non-carriers for people widowed or divorced before or after mid-life

missing for non-participants, we could not cross validate other results.

\section{DISCUSSION}

There is a substantial and independent association between marital status in mid-life and cognitive function later in life. People without a partner had twice the risk of developing cognitive impairment and Alzheimer's disease compared with people living with a partner. The risk for cognitive impairment was even higher for those without a partner both at mid-life and later life. The long follow-up period, the large and representative population based sample, adjustment for several possible confounders, robust significances, similar odds ratios for Alzheimer's disease and mild cognitive impairment, alternative calculations with consistent results, and similar odds ratios for non-participants all contribute to the credibility of our results. The increase in risk was significant for men and women, with slightly higher odds ratios for men. Because of small numbers in these sub-analyses, we cannot draw safe conclusions about possible sex differences.

\section{Beyond the brain reserve hypothesis}

As various forms of intellectual and social activity have been reported to protect against dementia, ${ }^{417}$ our observed associations with marital status might not seem surprising. The decreased risk of cognitive impairment later in life might reflect the effects of a high level of social and intellectual stimulation inherent in a couple relationship, consistent with the brain reserve hypothesis ${ }^{434}$ and indirectly with results from animal experiments on enriched environments. ${ }^{35} 36$

A more careful analysis of the results tells a somewhat different story. If the amount of time living without a partner was the critical risk factor, single life, here defined as never married, would obviously be associated with the highest risk. The odds ratios indicate, however, that despite having lived part of their lives in a couple relationship, the incidence of cognitive impairment was considerably higher in widowed people. Some specific risk factor seems to be associated with staying widowed, which to a lesser degree, if at all, is associated with other reasons for living without a partner.

Associations with cognitive impairment have been reported for several risk factors that might also be related to marital status, such as hypertension, high cholesterol concentration, obesity, physical inactivity, and smoking. ${ }^{112837-39}$ For depression there are almost no prospective studies with long follow-up and the evidence is more controversial. ${ }^{40} \mathrm{We}$ adjusted for all these factors without noticeably affecting the odds ratios.

\section{Reverse causation}

In the Honolulu-Asia aging study, Saczynski et al included marital status (married $v$ unmarried) in a social engagement index together with four other social activity variables. ${ }^{16}$ They performed regression analysis with adequate adjustments in relation to this combined index, rather than to marital status specifically, but did not significantly predict dementia an average of 27.5 years later. In later life, however, 4. 7 years before the first screening for dementia, the index was predictive of dementia. The authors discuss the predictive difference between mid-life and later life social engagement as possible evidence of reverse causation. There is evidence for subclinical effects up to nine years before a diagnosis of dementia, ${ }^{18-20}$ but with baseline measurements on average 21 years before diagnosis and a mean age of participants of 50 . 4 years (SD 6.0), reverse causation seems unlikely in our study, at least for mid-life marital status.

For the marital transition variable, however, including marital status in both mid-life and later life, reverse causation is possible, at least for those who lost their partners after mid-life. Odds ratios for this group were somewhat lower than for non-cohabitants at mid-life and considerably lower than those who lived without a partner both at mid-life and later life. These results seem to go against reverse causation as an explanation for those who lost their partner after mid-life. Saczynski et al measured social engagement in a wider sense, with marital status as only one of several indicators. ${ }^{16}$ The discrepancy in results could be explained by the various other social activities included in their social engagement index, some of which might be more sensitive to the effects of reverse causation than later life marital status.

\section{Marital status confounders}

In addressing a study by Verghese et al, ${ }^{13}$ Coyle argued that the protective effect of mental activities could be an epiphenomenon. ${ }^{41}$ By referring to the nun studies by Snowdon et al, ${ }^{42}$ Coyle made the point that nonrandom groups might initially differ in several ways besides the one being studied and that such differences might lie behind both the variable being studied and the risk of cognitive impairment later in life. This kind of initial bias, when people assign themselves to different groups, is a problem in non-experimental designs, including epidemiological research on dementia. ${ }^{43}$ So even if reverse causation seems improbable in our study because of mid-life baseline measurements and 


\section{WHAT IS ALREADY KNOWN ON THIS TOPIC}

Social networks and an active lifestyle have been reported to protect against dementia, but most studies are based on data collected later in life and have short follow-up

Reverse causation, a major methodological problem in these studies, means that participants might already be affected by subclinical dementia at baseline, thereby jeopardising causal conclusions

\section{WHAT THIS STUDY ADDS}

Being widowed from mid-life onwards was associated with the highest risk of cognitive impairment later in life with a highly significant odds ratio of 7.67 for Alzheimer's disease

Living without a partner for other reasons was also related to impaired cognitive functioning much later in life a long follow-up period, and even with adjustment for several relevant mid-life variables, it could always be argued that some other unknown factor produced a spurious relation between marital status and impairment later in life.

The contrasting odds ratios between people who were either cohabiting or widowed from mid-life onwards are of interest. These groups were originally similar in the sense that they both married at one time. The important point in this context is that those later widowed became single for reasons other than choice. It therefore seems farfetched to assume that those widowed, initially and systematically, should have differed from those who married and remained married. Still, the most dramatic difference in cognitive impairment later in life was found between these two groups.

\section{Towards a model of sociogenetic vulnerability}

It has been reported that apolipoprotein $\mathrm{E}$ e4 predicts the progression from mild cognitive impairment to Alzheimer's disease ${ }^{33}$ and also interacts with several risk factors for Alzheimer's disease. ${ }^{44}$ In the analyses where we combined marital and apolipoprotein E e4 status, the highest odds ratio was observed for those apolipoprotein E e4 carriers who were widowed or divorced both at mid-life and later life. The increase in risk was especially dramatic for Alzheimer's disease. Though these results should be interpreted with caution because of lack of statistical power to reliably estimate the interaction effects, they seem compatible with previous findings. Adverse effects on health and mortality have been linked to stressful experiences and negative emotions. ${ }^{45-48}$ It has also been suggested that immunological dysfunction, triggered by such events, might be an intervening factor in such a disease process. ${ }^{446}$ Loss of a partner, especially through death, has also been reported as a risk factor for a range of diseases ${ }^{49}$ and for immunological dysfunction. ${ }^{50}$

The tentative "sociogenetic" link indicated by our results could mean that psychosocial trauma of sufficient gravity and with long term negative emotional and disruptive immunological consequences could increase the risk of an existing genetic vulnerability leading to the development of the corresponding disease. For an apolipoprotein E e4 carrier, Alzheimer's disease might be the more probable disease outcome in such a scenario. Evidence for immunological dysfunction as a risk factor for Alzheimer's disease ${ }^{51}$ seems to add to the credibility of such a speculation.

\section{Implications for prevention}

For those who look for interventions to prevent the development of Alzheimer's disease, the results should be encouraging. If the proposed sociogenetic model proved valid, supportive intervention for individuals who have lost a partner might be a promising strategy in preventive health care. Our results also add to a growing body of evidence for the general importance of social factors in sustaining healthy brain functioning. A couple relationship might offer unique opportunities in this regard, perhaps not only through social and cognitive stimulation.

We are grateful to Håkan Locking, Centre for Labour Market Policy Research (CAFO), Växjö University, for statistical advice.

Contributors: MK, E-LH, AN, and HS participated in the planning, conception and design of the CAIDE study. AN and E-LH were involved in the design of baseline surveys, including marital status and signs of depression, and data collection both at mid-life and re-examination. MK and $\mathrm{E}-\mathrm{LH}$ were involved in diagnosing dementia and mild cognitive impairment at the re-examination, for which MK was the principal investigator. KH suggested the general concept and design of the present study, drafted the manuscript, and carried out statistical analyses. MK, SR, BW, and AHM contributed to further conceptual development of the study. Comments and suggestions were provided by SR, MK, BW, and AHM. All authors contributed in developing the manuscript further and interpreting the results. MK supervised the study and is guarantor. Funding: This study was funded by EVO-grant of Kuopio University Hospital (5772720), Academy of Finland (grants 103334 and 206951), EU grant QLK-2002-172, the Swedish Council for Working Life and Social Research, the Finnish Cultural Foundation, the Foundation of Juho Vainio, the Gamla Tjänarinnor Foundation, the Helsingin Sanomain 100vuotissäätiö, and the Gun and Bertil Stohne Foundation.

The funders had no role in study design; in the collection, analysis, and interpretation of data; in the writing of the report; or in the decision to submit the article for publication.

Competing interests: None declared.

Ethical approval: The CAIDE study has been approved by the ethics committee of Kuopio University Hospital $(24 / 97,07.02 .97)$ and by the ethics committee of Karolinska Institutet (04-103).

1 Ferri CP, Prince M, Brayne C, Brodaty H, Fratiglioni L, Ganguli M, et al. Global prevalence of dementia: a Delphi consensus study. Lancet 2005;366:2112-7.

2 Fratiglioni L, De Ronchi D, Aguero-Torres H. Worldwide prevalence and incidence of dementia. Drugs Aging 1999;15:365-75.

3 Comas-Herrera A, Wittenberg R, Pickard L, Knapp M. Cognitive impairment in older people: future demand for long-term care services and the associated costs. Int / Geriatric Psychiatry 2007;22:1037-45

4 Valenzuela MJ, Sachdev P. Brain reserve and dementia: a systematic review. Psychol Med 2006;36:441-54.

5 Katzman R. Education and the prevalence of dementia and Alzheimer's disease. Neurology 1993;43:13-20.

6 Qiu C, Backman L, Winblad B, Aguero-Torres H, Fratiglioni L. The influence of education on clinically diagnosed dementia incidence and mortality data from the Kungsholmen project. Arch Neurol 2001;58:2034-9.

7 Ngandu T, von Strauss E, Helkala EL, Winblad B, Nissinen A, Tuomilehto J, et al. Education and dementia: what lies behind the association? Neurology 2007;69:1442-50.

8 Del Ser T, Hachinski V, Merskey H, Munoz DG. An autopsy-verified study of the effect of education on degenerative dementia. Brain 1999;122:2309-19.

9 Marx J. Preventing Alzheimer's: a lifelong commitment? Science 2005;309:864-6.

10 Cotman CW, Berchtold NC. Exercise: a behavioral intervention to enhance brain health and plasticity. Trends Neurosci 2002;25:295-301. 
11 Rovio S, Kareholt I, Helkala EL, Viitanen M, Winblad B, Tuomilehto J, et al. Leisure-time physical activity at midlife and the risk of dementia and Alzheimer's disease. Lancet Neurol 2005;4:705-11.

12 Karp A, Paillard-Borg S, Wang HX, Silverstein M, Winblad B, Fratiglioni L. Mental, physical and social components in leisure activities equally contribute to decrease dementia risk. Dement Geriatr Cogn Disord 2006;21:65-73.

13 Verghese J, Lipton RB, Katz MJ, Hall CB, Derby CA, Kuslansky G, et al. Leisure activities and the risk of dementia in the elderly. N Engl J Med 2003;348:2508-16.

14 Barnes L, Evans D, Mendes C, de Leon CM, Wilson R, Bienias J. The relation of social networks, social engagement, and cognitive decline in an older bi-racial population. Gerontologist 2004;44:330.

15 Bassuk SS, Glass TA, Berkman LF. Social disengagement and incident cognitive decline in community-dwelling elderly persons. Ann Intern Med 1999;131:165-73.

16 Saczynski JS, Pfeifer LA, Masaki K, Korf ESC, Laurin D, White L, et al. The effect of social engagement on incident dementia-the Honolulu-Asia aging study. Am J Epidemiol 2006;163:433-40.

17 Fratiglioni L, Paillard-Borg S, Winblad B. An active and socially integrated lifestyle in late life might protect against dementia. Lancet Neurology 2004;3:343-53.

18 Gauthier S, Reisberg B, Zaudig M, Petersen RC, Ritchie K, Broich K, et al. Mild cognitive impairment. Lancet 2006;367:1262-70.

19 Mahncke HW, Bronstone A, Merzenich MM. Brain plasticity and functional losses in the aged: scientific bases for a novel intervention. In: Reprogramming the brain. Amsterdam: Elsevier Science, 2006:81-109.

20 Amieva HI, Jacqmin-Gadda HI, Orgogozo J-M, Le Carret N, Helmer C, Letenneur $L$, et al. The 9 year cognitive decline before dementia of the Alzheimer type: a prospective population-based study. Brain 2005;128:1093-101.

21 Robles TF, Kiecolt-Glaser JK. The physiology of marriage: pathways to health. Physiol Behav 2003;79:409-16.

22 Kiecolt-Glaser JK, Newton TL. Marriage and health: his and hers. Psychol Bull 2001;127:472-503.

23 Helmer C, Damon D, Letenneur L, Fabrigoule C, Barberger-Gateau P, Lafont S, et al. Marital status and risk of Alzheimer's disease: a French population-based cohort study. Neurology 1999;53:1953-8.

24 Van Gelder BM, Tijhuis M, Kalmijn S, Giampaoli S, Nissinen A, Kromhout D. Marital status and living situation during a 5 -year period are associated with a subsequent 10-year cognitive decline in older men: the FINE study. J Gerontol B Psychol Sci Soc Sci 2006;61:213-9.

25 Fratiglioni L, Wang HX, Ericsson K, Maytan M, Winblad B. Influence of social network on occurrence of dementia: a community-based longitudinal study. Lancet 2000;355:1315-9.

26 Bickel H, Cooper B. Incidence and relative risk of dementia in an urban elderly population-findings of a prospective field-study. Psychol Med 1994;24:179-92.

27 Yoshitake T, Kiyohara Y, Kato I, Ohmura T, Iwamoto H, Nakayama K, et al. Incidence and risk-factors of vascular dementia and Alzheimer's disease in a defined elderly Japanese population-the Hisayama study. Neurology 1995;45:1161-8.

28 Kivipelto M, Helkala EL, Laakso MP, Hanninen T, Hallikainen M, Alhainen $\mathrm{K}$, et al. Midlife vascular risk factors and Alzheimer's disease in later life: longitudinal, population based study. BMJ 2001;322:1447-51.

29 Kivipelto M, Helkala EL, Hanninen T, Laakso MP, Hallikainen M, Alhainen $\mathrm{K}$, et al. Midlife vascular risk factors and late-life mild cognitive impairment: a population-based study. Neurology 2001;56:1683-9.

30 Tsukamoto K, Watanabe T, Matsushima T, Kinoshita M, Kato H, Hashimoto Y, et al. Determination by PCR-RFLP of apo E genotype in a Japanese population. J Lab Clin Med 1993;121:598-602.
31 Folstein MF, Folstein SE, McHugh PR. "Mini-mental state". A practica method for grading the cognitive state of patients for the clinician. J Psychiatr Res 1975;12:189-98.

32 McKhann G, Drachman D, Folstein M, Katzman R, Price D, Stadlan EM. Clinical diagnosis of Alzheimer's disease: report of the NINCDS-ADRDA Work Group under the auspices of Department of Health and Human Services Task Force on Alzheimer's Disease. Neurology 1984;34:939-44.

33 Petersen RC, Smith GE, Ivnik RJ, Tangalos EG, Schaid DJ, Thibodeau SN, et al. Apolipoprotein E status as a predictor of the development of Alzheimer's disease in memory-impaired individuals. JAMA 1995;273:1274-8.

34 Fratiglioni L, Wang HX. Brain reserve hypothesis in dementia. J Alzheimers Dis 2007;12:11-22.

35 Diamond MC. Response of the brain to enrichment. Anais Da Academia Brasileira De Ciencias 2001;73:211-20.

36 Mohammed AH, Zhu SW, Darmopil S, Hjerling-Leffler J, Ernfors P, Winblad B, et al. Environmental enrichment and the brain. Prog Brain Res 2002;138:109-33.

37 Solomon A, Kareholt I, Ngandu T, Winblad B, Nissinen A, Tuomilehto J, et al. Serum cholesterol changes after midlife and latelife cognition: twenty-one-year follow-up study. Neurology 2007;68:751-6.

38 Kivipelto M, Ngandu T, Fratiglioni L, Viitanen M, Kareholt I, Winblad B, et al. Obesity and vascular risk factors at midlife and the risk of dementia and Alzheimer disease. Arch Neurol 2005;62:1556-60.

39 Reitz C, den Heijer T, van Duijn C, Hofman A, Breteler MMB. Relation between smoking and risk of dementia and Alzheimer disease: the Rotterdam study. Neurology 2007;69:998-1005.

40 Jorm AF. Is depression a risk factor for dementia or cognitive decline? A review. Gerontology 2000;46:219-27.

41 Coyle JT. Use it or lose it-do effortful mental activities protect against dementia? N Engl J Med 2003;348:2489-90.

42 Snowdon DA, Kemper SJ, Mortimer JA, Greiner LH, Wekstein DR, Markesbery WR. Linguistic ability in early life and cognitive function and Alzheimer's disease in late life. Findings from the Nun Study. JAMA 1996;275:528-32.

43 Gallacher I, Bayer A, Ben-Shlomo Y. Commentary: Activity each day keeps dementia away-does social interaction really preserve cognitive function? Int J Epidemiol 2005;34:872-3.

44 Kivipelto M, Rovio S, Ngandu T, Kareholt I, Eskelinen M, Winblad B, et al. Apolipoprotein E epsilon4 magnifies lifestyle risks for dementia: a population based study. J Cell Mol Med 2008;12:2762-71.

45 Kiecolt-Glaser JK, McGuire L, Robles TF, Glaser R. Emotions, morbidity, and mortality: new perspectives from psychoneuroimmunology. Annu Rev Psychol 2002;53:83-107.

46 Kiecolt-Glaser JK, McGuire L, Robles TF, Glaser R. Psychoneuroimmunology and psychosomatic medicine: back to the future. Psychosom Med 2002;64:15-28.

47 House JS, Landis KR, Umberson D. Social relationships and health. Science 1988;241:540-5.

48 Cohen S. Social relationships and health. Am Psychol 2004;59:676-84.

49 Prigerson HG, Bierhals AJ, Kasl SV, Reynolds CF, Shear MK, Day N, et al. Traumatic grief as a risk factor for mental and physical morbidity. Am J Psychiatry 1997;154:616-23.

50 Irwin M, Daniels M, Weiner H. Immune and neuroendocrine changes during bereavement. Psychiatr Clin North Am 1987;10:449-65.

51 Eriksson UK, Gatz M, Dickman PW, Fratiglioni L, Pedersen NL. Asthma, eczema, rhinitis and the risk for dementia. Dement Geriatr Cogn Disord 2008;25:148-56.

Accepted: 10 March 2009 